\title{
Dynamic tensile properties of a novel Kapton-type asymmetric polyimide derived from 2-phenyl-4,4'-diaminodiphenyl ether
}

Polymer Journal (2011) 43, 866-868; doi:10.1038/pj.2011.67; published online 27 July 2011

The excellent properties of aromatic polyimides (PIs) such as Kapton and Apical, which are derived from pyromellitic dianhydride (PMDA) and 4,4'-diamonidiphenyl ether (4,4'-ODA; DuPont Co. and Kaneka Co., respectively), are well known, including high dimensional stability and outstanding thermal and environmental stability. ${ }^{1-3}$ These properties are attributed not only to their rigid (planar and symmetric pyromellitimide) structures but also to the formation of highly ordered structures due to strong intermolecular interactions such as charge-transfer complexes. Accordingly, the aromatic PIs do not display high molecular mobility above the glass transition temperature $\left(T_{\mathrm{g}}\right)$, indicating that the processing conditions for molding were severe.

Yokota and co-workers ${ }^{4,5}$ previously reported that groundbreaking thermoplastic PIs derived from asymmetric and non-planar 2,3,3', $4^{\prime}$-biphenyltetracarboxylic dianhydride (a-BPDA) exhibited a large drop in the storage modulus $\left(E^{\prime}\right)$ above the $\mathrm{Tg}$ at $319^{\circ} \mathrm{C}$, as observed in dynamic mechanical analysis (DMA) measurements. These observed phenomena were found to be quite different from those of symmetric PI derived from 3,3',4,4'biphenyltetracarboxylic anhydride (s-BPDA), indicating that the irregular geometry of aBPDA restricted-free rotation and caused a decrease in the intensity of the intermolecular interaction. ${ }^{6}$ Meanwhile, amorphous PIs derived from non-planar and asymmetrical diamines have also been reported. Yang et al. ${ }^{8}$ reported that the PIs derived from PMDA and 3-phenyl-1,4-bis(4-aminophenoxy) benzene ( $\mathrm{p}$-TPEQ) showed a higher $T_{\mathrm{g}}$ at $286^{\circ} \mathrm{C}$ in comparison with bis $(4$-aminophenoxy)benzene-based PI $\left(T_{\mathrm{g}}=272{ }^{\circ} \mathrm{C}\right) .{ }^{8}$ Morikawa et al. ${ }^{9-11}$ also reported the preparation and thermal properties of aromatic
PIs derived from a series of phenyl groupsubstituted 4,4'-ODA derivatives. Particularly, bis(4-amino-2-biphenyl)ether-based PMDA PI showed significant improvements in solubility in polar aprotic solvents and a higher $T_{\mathrm{g}}$ at $303{ }^{\circ} \mathrm{C}$ than the aforementioned p-TPEQbased PIs.

We found that the asymmetric and aromatic PI derived from PMDA and 2-phenyl-4,4'diaminodiphenyl ether (p-ODA; Figure 1) showed a high $T_{\mathrm{g}}$ and a large drop in the $\mathrm{E}^{\prime}$ above the $T_{\mathrm{g}}$, which caused an amorphous structure to form, despite the PMDA/ODAtype backbone structure (Figure 2).
$\mathrm{PI}(\mathrm{PMDA} / \mathrm{p}-\mathrm{ODA})$ was prepared by conventional thermal imidization of the corresponding poly(amic acid), whose inherent viscosity is almost $0.8-1.0\left(\mathrm{dlg}^{-1}\right)$. The steric structure of $\mathrm{p}$-ODA had no significant influence on the polymerization reactivity. PI(PMDA/p-ODA) showed good chemical resistance and no solubility in common polar aprotic solvents such as $\mathrm{N}$-methylpyrrolidone.

Figure 3 shows the temperature dependency of the $E^{\prime}$ curves of the PI(PMDA/ p-ODA) and PI(PMDA $/ 4,4^{\prime}$-ODA) films that were obtained with DMA measurements in air.<smiles>Nc1ccc(Oc2ccc(N)cc2-c2ccccc2)cc1</smiles>

Figure 1 Structure of 2-phenyl-4,4'-diaminodiphenyl ether (p-ODA). p-ODA is an asymmetric diamine that is a $4,4^{\prime}$-diaminodiphenyl ether with a pendant phenyl group at the 2-position.

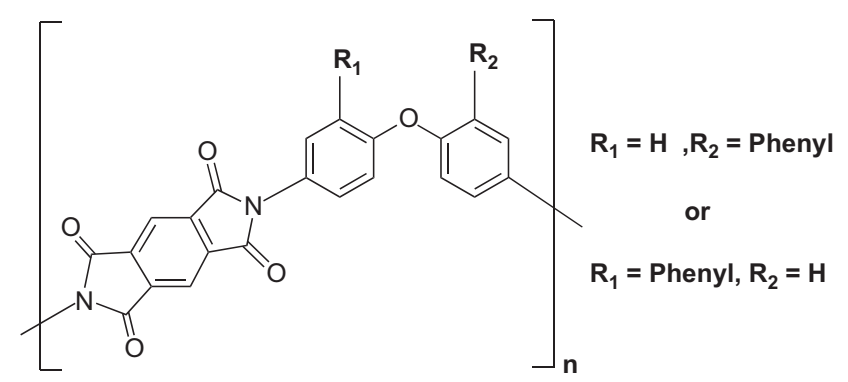

Figure 2 Structure of $\mathrm{PI}(\mathrm{PMDA} / \mathrm{p}-\mathrm{ODA})$. There are three possible types of repeated units in the PI(PMDA/p-ODA) chain: Head-to-head, head-to-tail and tail-to-tail. p-ODA, 2-phenyl-4,4'diaminodiphenyl ether; PI, polyimide; PMDA, pyromellitic dianhydride. 


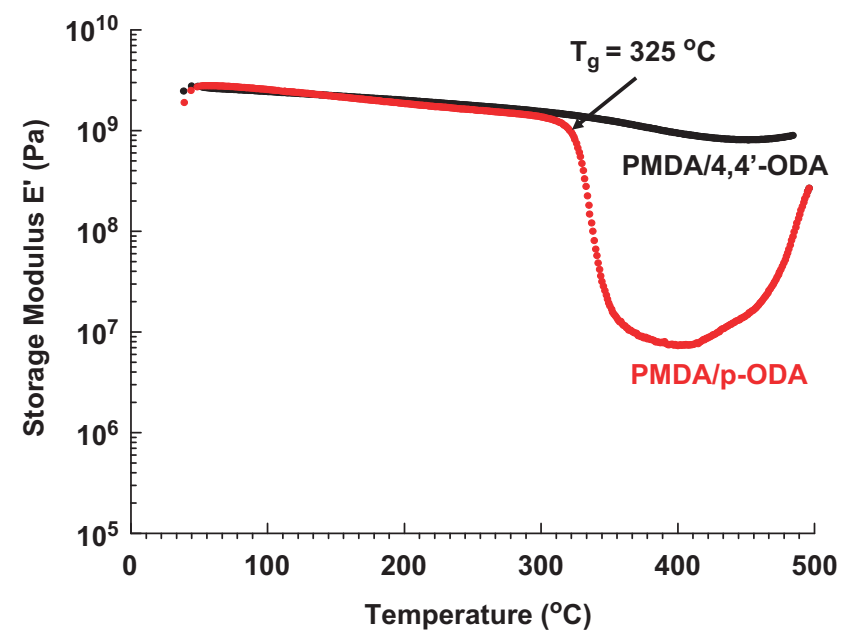

Figure 3 Dynamic mechanical analysis curves of $\mathrm{PI}\left(\mathrm{PMDA} / 4,4^{\prime}-\mathrm{ODA}\right)$ and $\mathrm{PI}(\mathrm{PMDA} / \mathrm{p}-\mathrm{ODA})$ films. The large drop in the $\mathrm{E}^{\prime}$ of $\mathrm{PI}(\mathrm{PMDA} / \mathrm{p}-\mathrm{ODA})$ that was seen in the dynamic mechanical analysis measurements is thought to be due to the existence of a phenyl group; this randomized repeated unit in the polymer backbone is thought to restrict the intra/intermolecular interactions of the polymer chains (see main text). p-ODA, 2-phenyl-4,4'-diaminodiphenyl ether; PI, polyimide; PMDA, pyromellitic dianhydride.

Table 1 Thermal and mechanical properties of PI(PMDA/p-ODA) and PI(PMDA/4,4'-ODA) films

\begin{tabular}{|c|c|c|c|c|c|c|}
\hline & \multicolumn{2}{|c|}{$\operatorname{Tg}\left({ }^{\circ} \mathrm{C}\right)$} & \multirow[b]{2}{*}{$T_{d 5}\left({ }^{\circ} C^{a}\right.$} & \multirow[b]{2}{*}{$E_{\text {ave }}(G P a)^{a}$} & \multirow[b]{2}{*}{$\sigma_{b, a v e}(M P a)^{b}$} & \multirow[b]{2}{*}{$\varepsilon_{b, \text { ave }}(\%)^{c}$} \\
\hline & DSC & DMA & & & & \\
\hline $\mathrm{PI}(\mathrm{PMDA} / \mathrm{p}-\mathrm{ODA})$ & 333 & 325 & 549 & 3.3 & 158 & 38.5 \\
\hline $\mathrm{PI}\left(\mathrm{PMDA} / 4,4^{\prime}-\mathrm{ODA}\right)$ & $-^{d}$ & $360^{e}$ & 571 & 3.2 & 279 & 68.6 \\
\hline
\end{tabular}

Abbreviations: p-ODA, 2-phenyl-4,4'-diaminodiphenyl ether; PI, polyimide; PMDA, pyromellitic dianhydride. aAverage values of modulus.

${ }^{b}$ Average values of tensile strength.

cAverage values of elongation at break.

dNot detected obviously.

eDetermined by the intersection of two tangent of storage modulus curve.

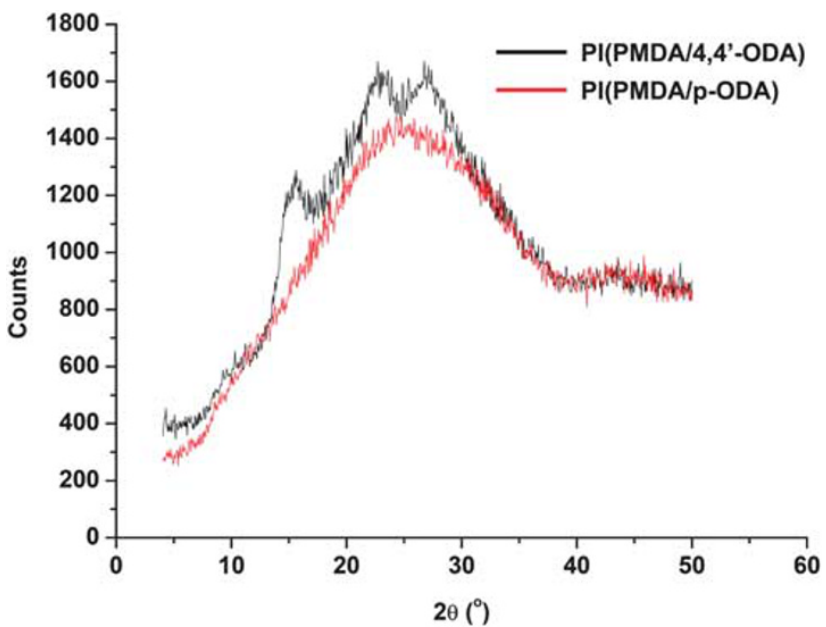

Figure 4 Reflection mode wide-angle X-ray diffraction patterns of PI(PMDA/4,4'-ODA; black line) and $\mathrm{PI}(\mathrm{PMDA} / \mathrm{p}-\mathrm{ODA}$; red line). PI(PMDA/4,4'-ODA) shows a typical crystallized pattern, as shown in references $1-3$ and 12 . PI(PMDA/p-ODA) showed a broad peak, indicating that $\mathrm{PI}(\mathrm{PMDA} / \mathrm{p}-\mathrm{ODA})$ formed an amorphous structure. p-ODA, 2-phenyl-4,4'-diaminodiphenyl ether; PI, polyimide; PMDA, pyromellitic dianhydride.
$\mathrm{PI}(\mathrm{PMDA} / \mathrm{p}-\mathrm{ODA})$ clearly showed a high $\mathrm{Tg}$ at $325^{\circ} \mathrm{C}$ and a significant drop in the $\mathrm{E}^{\prime}$ from $10^{9}$ to $10^{7} \mathrm{~Pa}$ (rubbery plateau region) above the $T_{\mathrm{g}}$. These data are thought to be attributable to the rotational inflexibility of the ether linkage of p-ODA, which restricted the conformational change of the PMDA $/ 4,4^{\prime}$-ODA backbone structure. The steric hindrance of the pendant phenyl groups of p-ODA also restricted the intra/intermolecular interactions of the PI chains.

The thermal and mechanical properties of $\mathrm{PI}(\mathrm{PMDA} / \mathrm{p}-\mathrm{ODA})$ that were determined by differential scanning calorimetry and tensile measurements are summarized in Table 1. $\mathrm{PI}(\mathrm{PMDA} / \mathrm{p}-\mathrm{ODA})$ showed high thermal stability, up to $400{ }^{\circ} \mathrm{C}$ in a nitrogen atmosphere, and a high $T_{\mathrm{d} 5}$ value of $549^{\circ} \mathrm{C}$ was recorded on the thermal gravimetry analysis curve. Moreover, PI(PMDA/p-ODA) was also found to be very tough based on the observed high tensile properties. These data were clearly attributed to the similarity in the chemical structure of $\mathrm{PI}(\mathrm{PMDA} / \mathrm{p}-\mathrm{ODA})$ compared with that of Kapton.

Figure 4 displays the reflection mode of the wide-angle $\mathrm{X}$-ray diffraction patterns of $\mathrm{PI}\left(\mathrm{PMDA} / 4,4^{\prime}-\mathrm{ODA}\right)$ and PI(PMDA/ p-ODA) films. A prominent annealing effect that results in molecular ordering is well known in conventional Kapton-type aromatic PI films. ${ }^{12}$ However, a PI(PMDA/p-ODA) film annealed at $400{ }^{\circ} \mathrm{C}$ yielded a typical amorphous pattern, which did not depend on the annealing temperature. The data obtained from the DMA measurements strongly supported the hypothesis that the pendant phenyl groups of $\mathrm{p}$-ODA restricted the intra/intermolecular interactions of PI chains to form amorphous structures.

In conclusion, the PI(PMDA/p-ODA) film exhibited good chemical resistance, a high $T_{\mathrm{g}}$, excellent mechanical properties and the formation of amorphous structures. The pendent phenyl group of p-ODA was surprisingly effective in causing typical PMDA-based aromatic PIs to yield an amorphous structure. The detailed second-order structure, the thermal and mechanical properties and the application possibilities for molding are now under investigation. We believe the aromatic PIs derived from asymmetric p-ODA diamine will greatly enhance the possibility of developing new heat-resistant composite materials with good processability. Studies on the detailed thermal and mechanical properties of phenylethynyl-terminated imide oligomers derived from PMDA and p-ODA and their cured resin are also now in progress. $^{13,14}$ 


\section{ACKNOWLEDGEMENTS}

This report is part of a series of research studies titled, 'Development of Novel Asymmetric Polyimides for Fiber-Reinforced Composite Materials with High Heat Resistance,' for which M Miyauchi received an Award for Encouragement of Research in Polymer Science; The Society of Polymer Science, Japan (2012). We thank Dr A Tamaki and Dr M Takeda at Seika Corporation for the monomer supply. We thank Professor M Kochi and Assistant Professor A Morikawa for fruitful discussions.

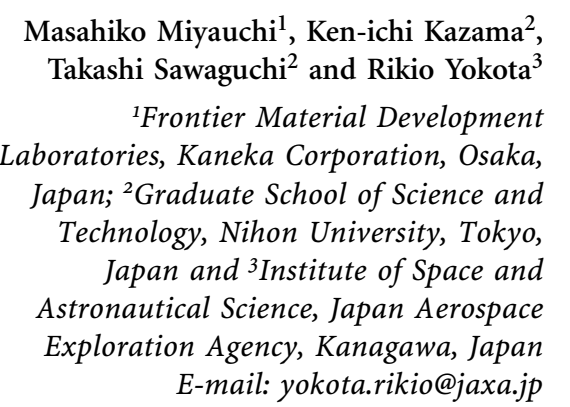

1 Polyimides: Fundamental and Applications (Marcel Dekker, New York, 1996).

2 Polyamic Acids and Polyimides. Synthesis, Transformations and Structure (CRC Press, Boca Raton, 1993).

3 Polyimides. Trends in Materials and Applications (Society of Plastic Engineers, Mid Hudson Section, New York, 1996).

4 Hasegawa, M., Sensui, N., Shindo, Y. \& Yokota, R. Structure and properties of asymmetric biphenyl type polyimides. Homo- and copolymers and blends. Macromolecules 32, 387-396 (1999)

5 Kochi, M., Chen, C., Yokota, R., Hasegawa, M. \& Hergenrother, P. Isomeric biphenyl polyimides. (II) glass transitions and secondary relaxation process. High Perform. Polym. 17, 335-347 (2005).

6 Yokota, R., Yamamoto, S., Yano, S., Sawaguchi, T., Hasegawa, M., Yamaguchi, H., Ozawa, H. \& Sato, R. Molecular design of resistant polyimides having excellent processability and glass transition temperature. High Perform. Polym. 13, S61-S72 (2001)

7 Yang, C. P. \& Chen, R. S. Polyimides Based on 2,5bis(4-aminophenoxy)biphenyl. J. Polym. Sci. Part A Polym. Chem. 40, 429-438 (2002).

8 Fang, X. Z., Yang, Z. H., Zhang, S. B., Gao, L. X. \& Ding, M. X. Polyimides derived from mellophanic dianhydride. Macromolecules 35, 8708-8717 (2002).

9 Morikawa, A., Furukawa, T. \& Moriyama, Y. Synthesis and characterization of novel aromatic polyimides from bis(4-amino-2-biphenyl) ether and aromatic tetracarboxylic dianhydrides. High Perform. Polym. 18, 593-602 (2006).

10 Morikawa, A., Furukawa, T. \& Moriyama, Y. Synthesis and characterization of novel aromatic polyimides from bis(4-amino-2-biphenyl)ether and aromatic tetracarboxylic dianhydrides. Polym. J. 37, 759-766 (2005).

11 Morikawa, A. Synthesis and Characterization of Aromatic Polyimides from Diamines having Substituents and Rigid Dianhydrides. In Recent Advances in Polyimides 2008 (eds Hasegawa, M., Ishida, Y., Kochi, M., \& Yokota R.) 1-6 (Meibunsha Co., Chiba, 2008).

12 Coburn, J. C. \& Pottiger, M. T. Advances in Polyimide Science and Technology (eds Feger, C., Khojasteh, M. M., \& Htoo. M. S.) 360 (Technomic, NewYork, 1993).

13 Miyauchi, M., Ishida, Y., Ogasawara, T. \& Yokota, R. Synthesis and properties of novel asymmetric additiontype imide oligomers with high solubility. In Recent Advances in Polyimides 2009 (eds. Takeichi, T., Kawauchi, T., \& Akahori, K.) 139-141 (Meibunsha Co., Aichi, 2009).

14 Miyauchi, M., Ishida, Y., Ogasawara, T. \& Yokota, R. Synthesis and properties of novel asymmetric addition-type imide resins based on Kapton ${ }^{\mathbb{R}}$-type structure. Proceedings of 14TH European Conference on Composite Materials 2010 ID:754 (Budapest, Hungary).

Supplementary Information accompanies the paper on Polymer Journal website (http://www.nature.com/pj) 